\title{
Disease Activity (Rheumatoid Arthritis Disease Activity Index-5) in Patients With Rheumatoid Arthritis and its Association With Quality of Life, Pain, Fatigue, and Functional and Psychological Status
}

\author{
İsmihan SUNAR,, ${ }^{1}$ Yeşim GARİP, ${ }^{2}$ Özlem YILMAZ, ${ }^{3}$ Hatice BODUR, ${ }^{3}$ Şebnem ATAMAN ${ }^{4}$ \\ ${ }^{1}$ Department of Internal Medicine, Medical Faculty of Ankara University, Division of Rheumatology, Ankara, Turkey \\ ${ }^{2}$ Department of Physical Medicine and Rehabilitation, Başak Medical Center, Ankara, Turkey \\ ${ }^{3}$ Department of Physical Medicine and Rehabilitation, Ankara Numune Training and Research Hospital, Ankara, Turkey \\ ${ }^{4}$ Department of Physical Medicine and Rehabilitation, Medical Faculty of Ankara University, Division of Rheumatology, Ankara, Turkey
}

\begin{abstract}
Objectives: This study aims to determine disease activity in patients with rheumatoid arthritis by Rheumatoid Arthritis Disease Activity Index-5 (RADAI-5), and to evaluate its association with the quality of life, pain, fatigue, and functional and psychological status.

Patients and methods: A total of 170 rheumatoid arthritis patients ( 30 males, 140 females; mean age $55.2 \pm 11.3$ years; range 28 to 82 years) were included in the study. Quality of life was evaluated by using Rheumatoid Arthritis Quality of Life Scale. Stanford Health Assessment Questionnaire was used for evaluating functional status, and Beck Depression Scale for psychological status. Level of fatigue was assessed by Fatigue Severity Scale. Disease activity was measured by using Disease Activity Score-28 (DAS28) and RADAI-5.

Results: Mean RADAI-5 score was 3.9 \pm 2.7 , and mean DAS28 score was $3.3 \pm 1.4$ (moderate disease activity). According to RADAI-5, $16.5 \%$ of the patients were in remission, $28 \%$ had mild disease activity, $27 \%$ had moderate disease activity, and $29 \%$ had high disease activity. RADAl-5 was strongly correlated with visual analog scale-pain, DAS28, Beck Depression Scale, Fatigue Severity Scale, Rheumatoid Arthritis Quality of Life Scale, and Health Assessment Questionnaire ( $r=0.91,0.81,0.78,0.75,0.75$ and 0.72 , respectively) ( $p<0.0001)$. Disease activity values measured with RADAI- 5 were compatible with the ones measured with DAS28.

Conclusion: RADAI-5 is a short, practical questionnaire that can easily be administered by the patient in a busy clinical practice setting. It can be used as a rheumatoid arthritis outcome measure to estimate the impact of the disease and evaluate health outcome in clinical studies.

Keywords: Depression; fatigue; pain; quality of life; rheumatoid arthritis.
\end{abstract}

Rheumatoid arthritis (RA) is a chronic, inflammatory disease characterized by chronic inflammation of the synovial joints leading to progressive joint destruction. ${ }^{1}$ It has multifactorial etiology and progression, including a range of immune, neuroendocrine, and psychosocial variables. It is partially known how these variables interact with one another and how they ultimately influence the disease process. $^{2}$

Disease activity, which is reflected by tender and swollen joint counts, levels of acute phase reactants, and patient's and physician's global assessments, is a good predictor of damage and physical disability, and an outcome measure, which is used to evaluate health outcome in clinical studies of patients with RA. ${ }^{3}$ Various disease activity scales have been used for measuring disease activity in RA; however, they are long, tedious, and may interfere with the flow of patient visits rather than contributing information to clinical care. ${ }^{4}$ For busy clinical settings, Leeb et al. ${ }^{5}$ developed a simplified version of the Rheumatoid Arthritis Disease Activity Index (RADAI) questionnaire, RADAI-5. 
RADAI-5 is a short and practical questionnaire that can be easily administered by the patient in a busy clinical practice setting. It takes less than 10 seconds to calculate. Its adaptation to Turkish language and validation were proven by Sunar et al. ${ }^{6}$

In this study, we aimed to determine disease activity in patients with RA by RADAI-5, and to evaluate its association with the quality of life (QoL), pain, fatigue, and functional and psychological status.

\section{PATIENTS AND METHODS}

The study included a total of 170 RA patients (30 males, 140 females; mean age 55.2 211.3 years; range 28 to 82 years) fulfilling the American Rheumatism Association 1987 revised criteria for the classification of $\mathrm{RA}^{7}$ Patient information regarding age, sex, and disease duration was recorded. Number of swollen and tender joints, and erythrocyte sedimentation rate and C-reactive protein levels were determined. QoL was evaluated by using Rheumatoid Arthritis Quality of Life Scale. ${ }^{8}$ The severity of pain was measured by $100 \mathrm{~mm}$ visual analog scale-pain. ${ }^{9}$ Turkish version of the Stanford Health Assessment Questionnaire was used to evaluate functional status. ${ }^{10}$ Psychological status was assessed by using Beck Depression Scale, ${ }^{11}$ and fatigue by Fatigue Severity Scale. ${ }^{12}$ Disease activity was measured by using the quadrivariate disease activity score-28 (DAS28), ${ }^{3}$ and RADAI-5. ${ }^{6}$

Rheumatoid Arthritis Disease Activity Index-5 is a 5 -item, self-administered RA-specific questionnaire that assesses global disease activity in last six months and current disease activity in terms of joint swelling and tenderness, pain, duration of morning stiffness and general health. Scores between 0.0 and 1.4 indicate remission, 1.6 and 3.0 low disease activity, 3.2 and 5.4 moderate disease activity, and $>5.6$ high disease activity. ${ }^{5,6}$ Turkish version of RADAI-5 is shown in Appendix 1.

All of the patients were informed about the study, and their written informed consent was taken. Medical research ethics committee of the training and research hospital approved

\section{Appendix 1. Turkish version of Rheumatoid Arthritis Disease Activity Index-5}

\section{Patient's name:}

Dear patient;

This questionnaire aims to determine aspects of your rheumatic disease exactly. Please answer the following questions regarding your rheumatic complaints. Do not leave any question unanswered.

For each question below, mark a number between 0 and 10 .

1. During the last six months, how active was your inflammatory joint disease (arthritis)?

\begin{tabular}{|l|l|l|l|l|l|l|l|l|l|l|l|}
\hline Not at all active & 0 & 1 & 2 & 3 & 4 & 5 & 6 & 7 & 8 & 9 & 10 \\
\hline
\end{tabular}

2. How active is your joint disease (arthritis) today in terms of sensitivity to pression and swellness of your joints?

\begin{tabular}{|c|c|c|c|c|c|c|c|c|c|c|c|c|}
\hline Not at all active & 0 & 1 & 2 & 3 & 4 & 5 & 6 & 7 & 8 & 9 & 10 & Extremely active \\
\hline
\end{tabular}

3. How severe is your joint pain (arthritis) today?

\begin{tabular}{|l|l|l|l|l|l|l|l|l|l|l|l|}
\hline No pain & 1 & 2 & 3 & 4 & 5 & 6 & 7 & 8 & 9 & 10 \\
\hline
\end{tabular}

4. How do you describe your current health status?

\begin{tabular}{|l|l|l|l|l|l|l|l|l|l|l|l|}
\hline Very good & 1 & 2 & 3 & 4 & 5 & 6 & 7 & 8 & 9 & 10 \\
\hline
\end{tabular}

5. Did your joints (hands) get stiff when you woke up this morning? If your answer is yes, how long did this stiffness continue?

\begin{tabular}{|l|l|l|l|l|l|l|l|l|l|l|}
\hline 0 & 1 & 2 & 3 & 4 & 5 & 6 & 7 & 8 & 9 & 10 \\
\hline
\end{tabular}


Table 1. Demographic and clinical patient data

\begin{tabular}{lccc}
\hline & Mean \pm SD & Median & Minimum-maximum \\
\hline Age (year) & $55.2 \pm 11.3$ & 56.00 & $28.0-82.0$ \\
Disease duration (month) & $160.1 \pm 99.9$ & 145.00 & $10-423.0$ \\
Erythrocyte sedimentation rate $(\mathrm{mm} / \mathrm{h})$ & $25.0 \pm 19.5$ & 19.5 & $2-100$ \\
C-reactive protein $(\mathrm{mg} / \mathrm{dL})$ & $10.0 \pm 13.5$ & 4.85 & $0.24-70.29$ \\
Disease activity score 28 & $3.3 \pm 1.4$ & 3.27 & $0.68-7.0$ \\
Rheumatoid arthritis disease activity index-5 & $3.9 \pm 2.7$ & 3.1 & $1.0-10.0$ \\
Health assessment questionnaire & $1.0 \pm 0.9$ & 0.75 & $0.0-3.0$ \\
Rheumatoid arthritis quality of life & $12.6 \pm 9.8$ & 10 & $0.0-30.0$ \\
Fatigue severity scale & $30.0 \pm 14.4$ & 27.5 & $12.0-62.0$ \\
Beck depression scale & $9.4 \pm 7.6$ & 7.0 & $0.0-34.0$ \\
Visual analog scale pain & $42.0 \pm 30.7$ & 38 & $0.0-100$ \\
\hline SD: Standard deviation. & & & \\
\hline
\end{tabular}

the study protocol. The study conforms to the provisions of the World Medical Association's Declaration of Helsinki.

\section{Statistical analyses}

Scores of the above-mentioned scales were obtained for statistical analyses. Depending on these values, the level of the linear relation between these scales was evaluated by correlation analysis. The presence of correlation between these scales was evaluated by Pearson's correlation coefficient. IBM SPSS for Windows version 21.0 software program (IBM Corp. Armonk, NY. USA) was used for statistical analyses. Statistical significance and the confidence interval was set at $\mathrm{p}<0.01$ and $99 \%$, respectively.

\section{RESULTS}

Demographic and clinical patient data including age, mean erythrocyte sedimentation rate and C-reactive protein levels, and mean scores of DAS28, RADAI-5, visual analog scale-pain, Health Assessment Questionnaire, Rheumatoid Arthritis
Quality of Life Scale, Fatigue Severity Scale, and Beck Depression Scale are given in Table 1.

Mean RADAI-5 score was 3.9 \pm 2.7 (median 3.1) (range 0-10), indicating moderate disease activity. At the time of the study, 28 patients (16.47\%) were in remission (RADAI-5: 0-1.4), 47 patients $(27.65 \%)$ had mild disease activity (RADAI-5: 1.6-3.0), 46 patients (27.06\%) had moderate disease activity (RADAI-5: 3.2-5.4), and 49 patients (28.82\%) had high disease activity (RADAI-5 >5.6).

Mean DAS28 score was $3.3 \pm 1.4$, indicating moderate disease activity. According to DAS28, 35 patients (20.59\%) were in remission (DAS28 52.6), 42 patients (24.71\%) had mild disease activity (DAS28: 2.6-3.2), 48 patients (28.24\%) had moderate disease activity (DAS28: 3.2-5.1), and 45 patients $(26.47 \%)$ had high disease activity (DAS28 $\geq 5.1$ ).

Correlations of RADAI-5 and DAS28 with other variables are given in Table 2. Analyses of correlation coefficients revealed that the strongest correlation of both DAS28 and RADAI- 5 was with visual analog scale-pain.

Table 2. Relationship between disease activity and quality of life, functional status, pain, fatigue, and depression

\begin{tabular}{cccccccc}
\hline & RAQoL & HAQ & VAS-pain & FSS & BDS & RADAI-5 & DAS28 \\
\hline RADAI-5 & & & & & & & \\
$r$ & $0.75^{*}$ & $0.72^{*}$ & $0.91^{*}$ & $0.75^{*}$ & $0.78^{*}$ & 1 & $0.81^{*}$ \\
$\mathrm{p}$ & $<0.0001$ & $<0.0001$ & $<0.0001$ & $<0.0001$ & $<0.0001$ & & $<0.0001$ \\
DAS28 & & & & & & 1 \\
$\mathrm{r}$ & $0.59^{*}$ & $0.59^{*}$ & $0.79^{*}$ & $0.63^{*}$ & $0.59^{*}$ & $0.81^{*}$ & 1 \\
$\mathrm{p}$ & $<0.0001$ & $<0.0001$ & $<0.0001$ & $<0.0001$ & $<0.0001$ & $<0.0001$ & \\
\hline
\end{tabular}

RAQoL: Rheumatoid Arthritis Quality of Life; HAQ: Health Assessment Questionnaire; VAS: Visual Analog Scale; FSS: Fatigue Severity Scale; BDS: Beck Depression Scale; RADAI-5: Rheumatoid Arthritis Disease Activity Index-5; DAS28: Disease Activity Score; " $p<0.01$ (significant). 


\section{DISCUSSION}

This study was conducted to determine the disease activity in Turkish RA patients, the impact of disease activity on QoL, physical function, pain, and psychological status and fatigue.

In our study, both RADAI-5 and DAS28 scores of the patients indicated moderate disease activity. $27.7 \%$ of our patients had low, $27.1 \%$ had moderate, and $28.8 \%$ had high disease activity, according to RADAI-5. These rates were $24.7 \%$, $28.2 \%$, and $26.5 \%$, respectively, according to DAS28. In another study performed in Turkey, $26.1 \%$ of the patients had low, $39.9 \%$ had moderate and $34 \%$ had high disease activity, according to DAS28. ${ }^{13}$ In a study from Colombia, where the disease activity was measured by using both American College of Rheumatology Improvement Criteria and clinical remission criteria of Pinals for RA, 24\% had very active RA, 60.7\% had moderately active RA, and $15.2 \%$ were in clinical remission. ${ }^{14}$ The frequency of patients with high disease activity seems to be higher in our series. This may be due to the patient selection criteria. Our group of patients was composed of mostly severe ones requiring regular controls in a tertiary hospital.

Disease activity values of our patients measured with RADAI-5 were compatible with the ones measured with DAS28. On the other hand, RADAI-5 was strongly correlated with DAS28. RADAI-5 has proven to be in line with more time consuming tools such as DAS28 and Clinical Disease Activity Index. ${ }^{6}$

Depression commonly occurs with RA, in the range of 13 to $20 \%{ }^{15}$ Its high prevalence in RA has been reported frequently in the literature. ${ }^{16-19}$ There are two hypotheses that systemic inflammation contributes to high prevalence of depressive symptoms in RA. First, disability from RA prevents patients from functioning the way they used to, thus generating feelings of loss and depression. Second, the proinflammatory cytokines that cause acute flares in RA may have a direct neural effect in promoting sickness behavior and corresponding depressive symptoms. It was reported that patients with major depression had increased plasma concentrations of C-reactive protein, interleukin 6 , and tumor necrosis factoralpha. ${ }^{20,21}$
Thus, we detected that disease activity, measured by using DAS28 and RADAI-5, was significantly correlated with depression. This association was previously shown in the study of Pollard et al.,22 where disease activity was measured by using DAS28. Similarly, Walker et al. $^{23}$ and Rathbun et al. ${ }^{24}$ confirmed that comorbid depression in RA was associated with worsening of disease activity and severity. On the other hand, Cadena et al., ${ }^{14}$ Wolfe and Michaud, ${ }^{25}$ and Sheehy et al. ${ }^{26}$ reported strong associations between psychological status and disease activity, confirming our data. Contrarily, Cordingley et al. ${ }^{27}$ found no statistically significant association between disease activity and depression levels, where depression was measured by using Hospital Anxiety and Depression Scale. Also, Heimans et al. $^{28}$ reported that depression severity was associated with symptoms of arthritis like pain and unwell being, but not disease activity.

In the present study, a statistically significant correlation between fatigue and disease activity was reported. This result conforms with the findings of Pollard et al. ${ }^{22}$ and Raterman et al. ${ }^{29}$ which confirm that fatigue has a negative impact on disease activity in patients with RA.

Furthermore, we detected a significant relationship between disease activity and functional status. This relationship was previously shown in the study of Molenaar et al. ${ }^{30}$ which reported that patients with $\mathrm{RA}$ in remission experienced minimal functional disability.

In our study, we reported that disease activity in RA had negative impact on QoL, which was measured with Rheumatoid Arthritis Quality of Life Scale, a RA-specific measure. Cadena et al. ${ }^{14}$ conducted a study among 79 RA patients in Colombia. They evaluated QoL by using Quality of life-Rheumatoid Arthritis Scale, another RA-specific measure. They demonstrated that RA activity significantly influenced QoL. Similarly, this finding was confirmed in previous studies by Prajs et al. ${ }^{31}$ and Houssien et al. ${ }^{32}$

To our knowledge, this is the first study to demonstrate that disease activity in RA is strongly correlated with five important items: QoL, depression, fatigue, pain, and functional status. Severity of pain ranked in first place among the variables that were associated with disease 
activity. A similar relationship was previously shown in the study of Garip et al. ${ }^{33}$

High disease activity has a negative impact on QoL, physical and psychological functions, and vitality. To our knowledge, this is the first study analyzing the association between disease activity and QoL, fatigue, and depression levels, where disease activity was assessed by using RADAI-5, which is an important scale reflecting disease activity. One particular advantage of RADAI-5 is that it can be used in crowded outpatient clinics, owing to the fact that it does not require acute phase reactants to be calculated. Moreover, it can be used as a RA outcome measure to estimate the impact of the disease and evaluate health outcome in clinical studies.

\section{Declaration of conflicting interests}

The authors declared no conflicts of interest with respect to the authorship and/or publication of this article.

\section{Funding}

The authors received no financial support for the research and/or authorship of this article.

\section{REFERENCES}

1. Balsa A, Pascual-Salcedo D, Martín J. Antibodies to citrullinated peptides in rheumathoid arthritis. Med Clin (Barc) 2007;128:668-73. [Abstract]

2. Walker JG, Littlejohn GO, McMurray NE, Cutolo M. Stress system response and rheumatoid arthritis: a multilevel approach. Rheumatology (Oxford) 1999;38:1050-7.

3. Prevoo ML, van 't Hof MA, Kuper HH, van Leeuwen MA, van de Putte LB, van Riel PL. Modified disease activity scores that include twenty-eight-joint counts. Development and validation in a prospective longitudinal study of patients with rheumatoid arthritis. Arthritis Rheum 1995;38:44-8.

4. Pincus T, Sokka T. Quantitative clinical assessment in busy rheumatology settings: the value of short patient questionnaires. J Rheumatol 2008;35:1235-7.

5. Leeb BF, Haindl PM, Maktari A, Nothnagl T, Rintelen B. Patient-centered rheumatoid arthritis disease activity assessment by a modified RADAI. J Rheumatol 2008;35:1294-9.

6. Sunar I, Yilmaz Tasdelen O, Garip Cimen Y, Bodur H. Translation and validation of the Turkish language version of the Rheumatoid Arthritis Disease Activity Index-5. Int $\mathrm{J}$ Rheum Dis 2014 Apr 12. [Epub ahead of print]

7. Arnett FC, Edworthy SM, Bloch DA, McShane
DJ, Fries JF, Cooper NS, et al. The American Rheumatism Association 1987 revised criteria for the classification of rheumatoid arthritis. Arthritis Rheum 1988;31:315-24.

8. Kutlay $\mathrm{S}$, Küçükdeveci $\mathrm{AA}$, Gönül $\mathrm{D}$, Tennant A. Adaptation and validation of the Turkish version of the Rheumatoid Arthritis Quality of Life Scale. Rheumatol Int 2003;23:21-6.

9. Price DD, McGrath PA, Rafii A, Buckingham B. The validation of visual analogue scales as ratio scale measures for chronic and experimental pain. Pain 1983;17:45-56.

10. Küçükdeveci AA, Sahin H, Ataman S, Griffiths B, Tennant A. Issues in cross-cultural validity: example from the adaptation, reliability, and validity testing of a Turkish version of the Stanford Health Assessment Questionnaire. Arthritis Rheum 2004;51:14-9.

11. Beck AT, Ward CH, Mendelson M, Mock J, Erbaugh J. An inventory for measuring depression. Arch Gen Psychiatry 1961;4:561-71.

12. Gencay-Can A, Can SS. Validation of the Turkish version of the fatigue severity scale in patients with fibromyalgia. Rheumatol Int 2012;32:27-31.

13. Bodur H, Ataman S, Akbulut L, Evcik D, Kavuncu V, Kaya T, et al. Characteristics and medical management of patients with rheumatoid arthritis and ankylosing spondylitis. Clin Rheumatol 2008;27:1119-25.

14. Cadena J, Vinaccia S, Pérez A, Rico MI, Hinojosa $\mathrm{R}$, Anaya JM. The impact of disease activity on the quality of life, mental health status, and family dysfunction in colombian patients with rheumatoid arthritis. J Clin Rheumatol 2003;9:142-50.

15. Dougados M, Soubrier M, Antunez A, Balint $\mathrm{P}$, Balsa A, Buch $\mathrm{MH}$, et al. Prevalence of comorbidities in rheumatoid arthritis and evaluation of their monitoring: results of an international, cross-sectional study (COMORA). Ann Rheum Dis 2014;73:62-8.

16. Matcham F, Rayner L, Steer S, Hotopf M. The prevalence of depression in rheumatoid arthritis: a systematic review and meta-analysis. Rheumatology (Oxford) 2013;52:2136-48.

17. Covic T, Cumming SR, Pallant JF, Manolios N, Emery P, Conaghan PG, et al. Depression and anxiety in patients with rheumatoid arthritis: prevalence rates based on a comparison of the Depression, Anxiety and Stress Scale (DASS) and the hospital, Anxiety and Depression Scale (HADS). BMC Psychiatry 2012;12:6.

18. Sharpe L, Sensky T, Allard S. The course of depression in recent onset rheumatoid arthritis: the predictive role of disability, illness perceptions, pain and coping. J Psychosom Res 2001;51:713-9.

19. Pincus T, Griffith J, Pearce S, Isenberg D. Prevalence of self-reported depression in patients with rheumatoid arthritis. Br J Rheumatol 1996;35:879-83.

20. Tillmann T, Krishnadas R, Cavanagh J, Petrides KV. Possible rheumatoid arthritis subtypes in terms of 
rheumatoid factor, depression, diagnostic delay and emotional expression: an exploratory case-control study. Arthritis Res Ther 2013;15:45.

21. Margaretten M, Julian L, Katz P, Yelin E. Depression in patients with rheumatoid arthritis: description, causes and mechanisms. Int $\mathrm{J}$ Clin Rheumtol 2011;6:617-623.

22. Pollard LC, Choy EH, Gonzalez J, Khoshaba B, Scott DL. Fatigue in rheumatoid arthritis reflects pain, not disease activity. Rheumatology (Oxford) 2006;45:885-9.

23. Walker JR, Graff LA, Dutz JP, Bernstein CN. Psychiatric disorders in patients with immune-mediated inflammatory diseases: prevalence, association with disease activity, and overall patient well-being. $\mathrm{J}$ Rheumatol Suppl 2011;88:31-5.

24. Rathbun AM, Reed GW, Harrold LR. The temporal relationship between depression and rheumatoid arthritis disease activity, treatment persistence and response: a systematic review. Rheumatology (Oxford) 2013;52:1785-94.

25. Wolfe F, Michaud K. Predicting depression in rheumatoid arthritis: the signal importance of pain extent and fatigue, and comorbidity. Arthritis Rheum 2009;61:667-73.

26. Sheehy C, Murphy E, Barry M. Depression in rheumatoid arthritis--underscoring the problem. Rheumatology (Oxford) 2006;45:1325-7.

27. Cordingley L, Prajapati R, Plant D, Maskell D, Morgan C, Ali FR, et al. Impact of psychological factors on subjective disease activity assessments in patients with severe rheumatoid arthritis. Arthritis Care Res (Hoboken) 2014;66:861-8.

28. Heimans L, Wevers-de Boer KV, Visser K, Ronday HK, Steup-Beekman GM, van Oosterhout M, et al. The relationship between disease activity and depressive symptoms severity and optimism-results from the IMPROVED study. Clin Rheumatol 2013;32:1751-7.

29. Raterman HG, Hoving JL, Nurmohamed MT, Herenius MM, Sluiter JK, Lems WF, et al. Work ability: a new outcome measure in rheumatoid arthritis? Scand $\mathrm{J}$ Rheumatol 2010;39:127-31.

30. Molenaar ET, Voskuyl AE, Dijkmans BA. Functional disability in relation to radiological damage and disease activity in patients with rheumatoid arthritis in remission. J Rheumatol 2002;29:267-70.

31. Prajs K, Flicinski J, Brzosko I, Przepiera-Bedzak H, Ostanek L, Brzosko M. Quality of life and activity of disease in patients with rheumatoid arthritis. Ann Acad Med Stetin 2006;52:39-43. [Abstract]

32. Houssien DA, McKenna SP, Scott DL. The Nottingham Health Profile as a measure of disease activity and outcome in rheumatoid arthritis. $\mathrm{Br} \mathrm{J}$ Rheumatol 1997;36:69-73.

33. Garip Y, Eser F, Bodur H. Health-related quality of life in rheumatoid arthritis: comparison of RAQoL with other scales in terms of disease activity, severity of pain, and functional status. Rheumatol Int 2011;31:769-72. 